\title{
Reversible Splenic Enlargement Associated with Pregnancy in a Patient with Gaucher's Disease
}

\author{
Lt Col K R Young, \\ MRCOG, RAMC, Consultant Obstetrician \\ Lt Col M J Payne, \\ MRCS, LRCP, FRCS(Ed), RAMC, Consultant Surgeon \\ Cambridge Military Hospital, Aldershot
}

SUMMARY: A previously unreported complication of Gaucher's disease and pregnancy is described. The problenp associated with pregnancy and Gaucher's disease are discussed and the literature reviewed.

\section{Introduction}

Gaucher's disease is a rare inborn error of metabolism in which there is a deficiency of the enzyme glucocerebrosidase in cells of the reticulo endothelial system. It is transmitted as an autosomal recessive and antenatal diagnosis is now becoming available. Splenectomy has in the past been a common treatment and is still indicated when splenic enlargement causes mechanical difficulties $^{1}$. Goldblatt and Beighton ${ }^{2}$ reported 19 pregnancies in 11 women, only one of whom apparently had been subjected to splenectomy, but this paper was not available to us during the management of our patient. A search of literature for the previous 12 years failed to find a single case report of pregnancy associated with Gaucher's disease and an intact spleen.

\section{Case Report}

The patient was a 26 year old married woman in her third pregnancy. The first had ended in miscarriage at 12 weeks and the second was terminated by surgical induction at 38 weeks because of splenic enlargement. The child, a healthy male, weighed $3.9 \mathrm{Kgs}$. The patient is a known case of Gaucher's discase Type 1 and two of her four siblings also have the disease. One sister has had a splenectomy and is suffering from accelerated joint degeneration. The patient was first seen at 11 weeks gestation with an apparently normal pregnancy. The spleen was palpable $4.0 \mathrm{cms}$ below the costal margin and the liver edge was not recorded as palpable. The hacmoglobin was $9.7 \mathrm{~g} / \mathrm{dl}$ and the platelet count $57 \times$ $10^{9} / \mathrm{L}$. Liver function tests were normal. During the pregnancy the haematological indices were monitored monthly. Haemoglobin varied between $9.3 \mathrm{~g} / \mathrm{dl}$ and 10.3 $\mathrm{g} / \mathrm{dl}$, with platelets between 40 and $76 \times 10^{9} / \mathrm{L}$. Liver function tests remained within the normal ranges for pregnancy.

In the course of the pregnancy remarkable splenomegaly occurred. At 15 wecks the spleen was 9.0 $\mathrm{cms}$ below the costal margin and at 22 weeks, was $16 \mathrm{cms}$ below the costal margin. By 30 weeks the spleen had enlarged to the umbilicus and the liver edge was also palpable $3.0 \mathrm{cms}$ below the right costal margin. At this point there was grave concern over the possibility splenic rupture from minor trauma and the patient wa admitted to hospital. The liver and spleen continued toㅛㅐ enlarge, and we became concerned that pressure from the contracting uterus might be enough to rupture thw spleen. The patient was therefore delivered at 34 weele by elective Caesarean section, with a consultant surgeon

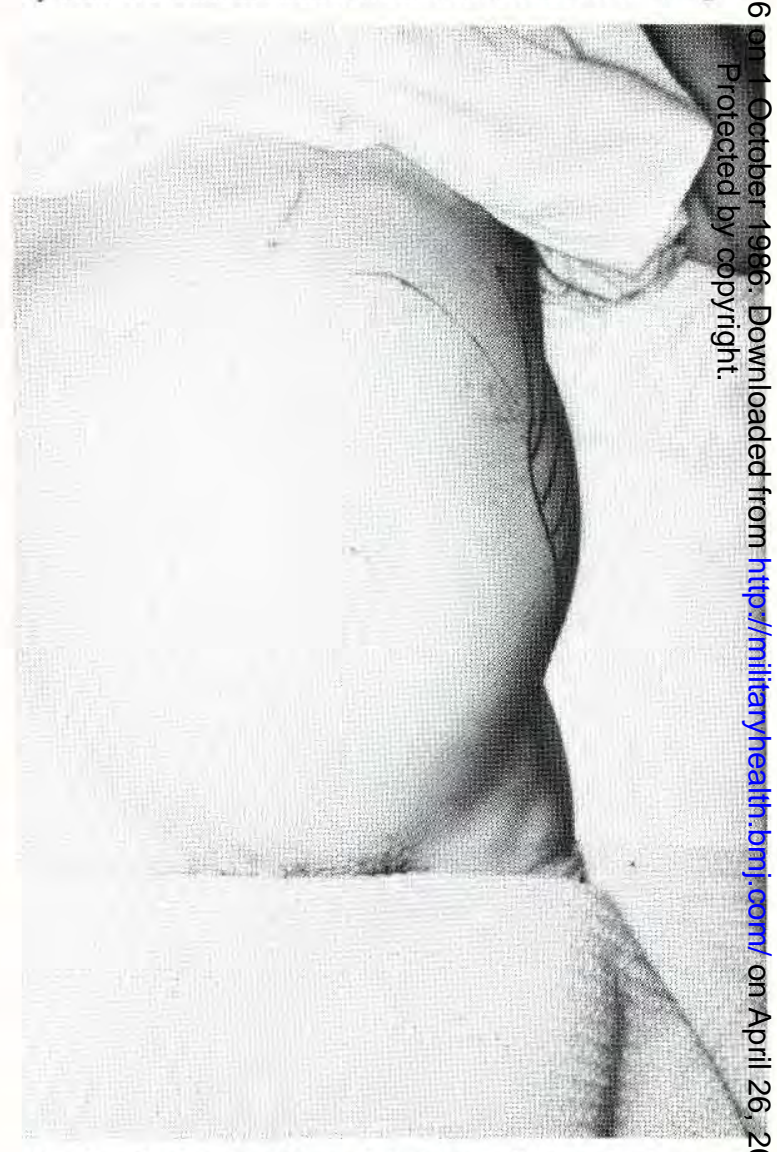

Fig. 1. Surface markings of the uterus, liver and spleen at $3 \AA$ weeks, just prior to delivery. 
present in case of trauma to the spleen. Immediately following delivery of a female child weighing $2.29 \mathrm{Kgs}$ the spleen rotated medially and came to lie with the tip level with the left iliac crest. The surface markings of the uterus, liver and spleen prior to delivery are shown in Fig. 1. Both mother and baby were discharged on fourteenth day following delivery and the mother was given exemption from wearing motor car seat belts for one year. At postnatal review the spleen had shrunk to $12 \mathrm{cms}$ below the costal margin and at three months to 4 cms below the costal margin. The liver was just palpable at three months.

\section{Discussion}

Goldblatt's report ${ }^{2}$ adds very significantly to the body of literature on this subject. It confirms that pregnancy has no adverse effect on the course of Gaucher's discase and that there are no significant obstetric problems associated with the condition. Close haematological surveillance is required but active intervention is rarely necessary ${ }^{2,3}$. It is reassuring that splenic rupture in labour has never been reported. Nevertheless, rupture of the cnlarged Gaucher spleen may result from minor trauma ${ }^{4}$ and none of the reported labours occurred in association with such an enlarged spleen.

Normally the splenic cnlargement of Gaucher's disease is not reversible, being caused by deposition of Gaucher cells within the spleen and Goldblatt ${ }^{2}$ states categorically that enlargement of the liver and splcen did not occur during pregnancy. We take the view that the enlargement which occurred in this case may well have been the result of portal hypertension. It is interesting to speculate on whether the splecn would then be more or less prone to injury from minor trauma.

Nevertheless we would certainly not advocate routine Caesarean section or pre-term delivery. All the evidence suggests that women with Gaucher's disease tolerate pregnancy well and that there is little or no increase in risk. It is likely that splenectomy will become less common in the future as success is achieved with bone marrow transplantation ${ }^{5}$, and the behaviour of the Gaucher spleen in pregnancy will then become more amenable to investigation.

\section{REFERENCES}

1. Aufses A H Jr and SALKY B M. The Surgical Management of Gaucher's Disease. Progress in Clinical and Biological Research. Alan R Liss Inc, New York. 1982: 603.

2. GOIDBLATT J and BEIGHTON P. Obstetric Aspects of Gaucher's Disease. Br J Obstet Gynaecol 1985; 92: 145-149.

3. Houlto: M C and JACKSON M B. Gaucher's Disease and Pregnancy. Obstet Gynaecol 1978; 51: 5:619-620.

4. Case Records of the Massachusetts General Hospital. Case No: 31321. N Eng J Med 1945; 233: 189-191.

5. Hobbs J R. Personal Communication. 1984.

\section{NOTICE OF THE ANNUAL GENERAL MEETING \& LECTURE OF THE HISTORY OF NURSING GROUP, ROYAL COLLEGE OF NURSING}

The Annual General Mecting of the History of Nursing Group, Royal College of Nursing, will take place on Tuesday, 18 November 1986 at 2.00 p.m., open to Members only.

The Annual Lecture 1986 will follow at 2.30 p.m. in the Cowdray Hall at RCN Headquarters, London.

The speaker will be Professor Olive Banks of the Victorian Studies Centre, Leicester University, and her subject will be "The Role of Religion and Women's Campaigns in the 19th Century". Professor Banks has written a book entitled "Faces of Feminism".

As this meeting is an open one, the subject will have an interest not only to nurses but all involved in women's movement.

Further information/application forms are available from the Director of Education, Royal College of Nursing, 20 Cavendish Square, London W1M OAB. 